\title{
Reformulation and priorities for reducing energy density; a survey on fat content in cakes and biscuits sold in British supermarkets
}

\author{
Roberta Alessandrini, Fengjun He, Kawther M. Hashem, Monique Tan and \\ Graham A MacGregor \\ Wolfson Institute of Preventive Medicine, Queen Mary University of London, London, United Kingdom
}

\section{Abstract}

Cakes and biscuits are widely consumed foods and are important contributors of energy, total and saturated fat and sugar in British diets. So far, the UK government has prompted the food industry to reduce energy density in cakes and biscuits mainly through sugar reformulation. However, a government led evaluation has shown that reducing only sugar has lowered energy density minimally. To assess whether total and saturated fat reformulation could be an additional and more effective mechanism for reducing product energy density we conducted a cross-sectional survey of pre-packed cakes and biscuits available in nine UK supermarkets. We collected nutrition information from product packaging. In cakes $(\mathrm{n}=381)$, the mean total fat content was $17.9 \pm 5.2 \mathrm{~g} / 100 \mathrm{~g}(39 \%$ of the overall energy); range $(1.4-35.6 \mathrm{~g} / 100 \mathrm{~g})$. The average saturated fat content in cakes was $5.9 \pm 3.4 \mathrm{~g} / 100 \mathrm{~g}$ ( $13 \%$ of the overall energy); range $(0.3-20 \mathrm{~g} / 100 \mathrm{~g})$. The average sugar content in cakes was $36.6 \pm 7.6(34 \%$ of the overall energy); range $(11.3-62.0 \mathrm{~g} / 100 \mathrm{~g})$. In biscuits $(\mathrm{n}=481)$ the mean total fat content was $21.8 \mathrm{~g} \pm 6.3 \mathrm{~g} / 100 \mathrm{~g}(40 \%$ of the overall energy); range $(0.7-38.9 \mathrm{~g} / 100 \mathrm{~g})$ and the average saturated fat content was $11.4 \pm 4.9 \mathrm{~g} / 100 \mathrm{~g}$ ( $23 \%$ of the overall energy); range $(0.3-22.3 \mathrm{~g} / 100 \mathrm{~g})$. The average sugar content in biscuits was $30.0 \pm 9.2(23 \%$ of the overall energy); range $(12.0-74.0 \mathrm{~g} / 100 \mathrm{~g})$. In both cakes and biscuits total and saturated fat, but not sugar content, was positively correlated with energy density. According to the nutrient profiling system used by the government, $57 \%$ of cakes and $75 \%$ of biscuits would receive a red (high) label for total fats; $54 \%$ of cakes and $88 \%$ of biscuits and would receive a red label for saturated fat.

Our results show that cakes and biscuits sold in UK supermarkets are high in total and saturated fat, and that fat content contributes substantially to product energy density. We observed a large variation in total and saturated fat content within each product category. This finding indicates that reformulation to reduce total and saturated fat and energy density is possible as some manufacturers are already producing cake and biscuits with a more healthful nutrient composition and lower energy density. Fat reformulation in cakes and biscuits and similar products would effectively reduce energy density and calorie intake and thereby prevent obesity. We recommend that fat reformulation should be implemented simultaneously with sugar reformulation and to be focussed where possible on saturated fat, as this will have the additional and independent beneficial effect of lowering LDL cholesterol.

\section{Conflict of Interest}

"There is no conflict of interest" 